\title{
Complementary Feeding Knowledge of Mother and Nutritional Status of Infant/Young Children (6-23 Months) in Ethiopia
}

\author{
Firdisa Birru Goshu* \\ *Lecturer of Economics, Wollega University, College of Business and Economics, P.O.Box 395, Nekemte, \\ Ethiopia
}

\begin{abstract}
Improving infant and young child feeding practices in children aged 6-23 months is critical to improved nutrition, health, and development. This paper examined the complementary feeding knowledge, attitude and practice of mothers and nutritional status of infants/young children in Jima Ganati District employing the cross sectional survey data conducted among 353 mothers of children aged 6-23 months. The result from the logit regression Education levels of mothers, age of mothers and mother occupation had a significant effect on mothers' complementary feeding knowledge, attitude and nutritional status of infants/young children. In this study $54.6 \%$, $60.4 \%$ and $34.6 \%$ of mothers had good knowledge, attitude and practice on complementary feeding respectively.
\end{abstract} Keywords: complementary feeding; knowledge; attitude; logit model; nutritional status.

DOI: $10.7176 / \mathrm{JCSD} / 49-02$

Publication date:June $30^{\text {th }} 2019$

\section{Introduction}

In the manufacturing sector today, human capital is still essential for most factories to carry out a variety of Poor infant feeding practices are known to have adverse consequences on the health and nutritional status of children, which in turn have consequences on the development of the child both physically and mentally (UNICEF, 2006). In Ethiopia almost $70 \%$ of the infants were reported to sub-optimally breastfed and $24 \%$ of death among infants was attributed to poor and inappropriate breastfeeding practices. According to $2011 \mathrm{EDHS}$, at six months of age $49 \%$ of infants/young children were timely got complementary feeding. Recent report revealed that $27 \%$ of the mothers early offer water, butter and various types of food to nourish their children, thus reducing the percentage of exclusively breastfeed and increasing the percentage of receiving complementary food at very young age (Tamiru and Mohammad, 2013).

According EDHS (2011) and Egata et al, (2013), 52\% of infants started breastfeeding with one hour of birth and exclusive breastfeeding during first six months. About (49\%) of children 6-8 months consumed solid, or soft foods and $5 \%$ of children were fed minimum dietary diversity and $4 \%$ of children fed minimum meal frequency per day while $96 \%$ of childrencontinued breast feeding at one year, and $82 \%$ continued at 2 year. only $4 \%$ of children 6-23 months living with mothers are fed in accordance with IYCF practices and $66 \%$ of children under the age of two receive age-appropriate breast feeding. In Ethiopia, $66.3 \%$ of the mothers/caregivers knew that they should breastfeed for at least two or more years (UNICEF, 2014). Although, studies have documented the behavior of the mothers/caregivers in the other Regions of Ethiopia, such studies are scanty on pastoralist community and in this specific area; no such study has been conducted. Therefore, this study was designed to examine complementary feeding knowledge, attitude and practices of mothers/caregivers and nutritional status of infants in Jima Ganati district.

\section{Related Literature}

According to PAHO/WHO (2003) complementary feeding can be defined as, the process starting when breast milk alone is no longer sufficient to meet the nutritional requirements of infants and therefore other foods and liquids are needed, along with breast milk. Complementary feeding is extremely essential and typically covers the period from 6 to 24 months of age. Well over two-thirds of these deaths, which are often associated with inappropriate feeding practices, occur during the first year of life. An estimated 32\% or 186 million children below five years of age in developing countries are stunted and about $10 \%$ or 55 million are wasted (WHO, 2003). Motherse knowledge on complementary feeding practices can influence a child's nutritional status thus this study reviewed literature on mothers"e knowledge on complementary feeding practices and mothers"; practices in terms of; frequency of meals, dietary diversity, timely introductions of complementary foods, use of bottle feeding and hygiene during complementary feeding.

A mother's complementary feeding practices are determined by a number of factors often out of her immediate control including local water and food availability and accessibility, employment, and environmental conditions. Knowledge of appropriate timing of introduction of foods and types of foods is another factor often complicated by lack of resources. Infants express hunger, satiety, and preferred feeding methods through a variety of behaviors from which a mother acts upon according to her interpretation. Infants do not necessarily have the capability to choose which types of foods and beverages they should consume; this responsibility usually lies with the mother 
(WHO, 2001. cited in Schwartz H.L (2008).

\subsection{Effects of Complementary Feeding on Infants/young children}

Inappropriate complementary feeding practices are a major cause of the onset of malnutrition in infants. From six months onward, when breast milk alone is no longer sufficient to meet all the nutritional requirements, infants enter a particularly vulnerable period of complementary feeding during which they make a gradual transition to eating family foods (WHO, 2001). Poor nutrition intake during this critical period of development can increase the risk of morbidity and mortality and can result in compromised growth and cognitive function in later years (Schwartz, 2008). Increasing the length of time between births is important given that a newborn often takes a mothers' time away from other infants. This concomitantly results in cessation of breastfeeding of existing infants or introducing inappropriate foods too early, which has been known to lead to increased morbidity and mortality in infants (Jacobsen, 2008).

\subsection{Empirical studies on Complementary Feeding on Infants/young children}

Sub-optimal infant feeding is common with single mothers (Tampah-Naah \&Kumi-Kyereme, 2014). Studies concluded that single mothers were less likely to breastfeed and complementary feeding adequately and longer due to absence of partners' support and confidence compared with married mothers (Lamontagneet al., 2008; Olayemiet al., 2014). Greater household income and assets directly raise the ability to purchase sufficient quantities of nutritious foods, clean water, clothing, adequately-ventilated housing, fuel for proper cooking, safe storage of food, personal hygiene items, and health services (Boyle et al., 2006; Hong \& Mishra, 2006; Mogeset $a l, 2017)$. Young mothers were more likely to have malnourished children than the elder mother. This can be associated with the experience the mother has had and lack of social support system for the young mothers associated with urbanization (Shitemi, 2018). Studies had shown that older maternal age is associated with exclusive breastfeeding and longer duration of breastfeeding (Ukegbuet alt., 2011).

The study conducted at Nairobi, Kenya indicated that mothers that were engaged in full time or causal work were associated with improper complementary feeding and care of their infants/young children (Olatona, 2018). In early infancy there were virtually no differences between boys and girls in most of the countries studied. In Kenya, Rwanda, Zimbabwe, Guatemala, and Paraguay boys are more likely to be breastfed and complementary foods fed than girls by about 5 to 10 percentage points (Haggerty \& Rutstein, 1999; Yeshwamebrat, 1995). Hence mothers lean towards longer breast and complementary feeding duration on the part of the male. Continued breastfeeding and the timely transition to adequate complementary food is basic to keep health of a child (WHO, 2010). In Ethiopia, 57\% of all under-five deaths are highly associated with abrupt cessation of breastfeeding and infectious diseases, but it is closely linked to gap of knowledge on how to feed appropriately (ORC Macro, 2012).

\subsection{Risks of giving complementary foods early and late of infant and young children} Table 1: Risks of giving complementary foods early

- A child does not need food yet, and they may displace breast milk.

- As a consequence the mother produces less milk and later it may more difficult to meet the child's nutritional needs.

- A child receive less of the protective factors in breast milk, so the risks of illness increases;

- risks of diarrhea also increases because complementary food may not be clean as breast milk.

- The complementary foods given are usually watery porridges or soups because they are easy for babies to eat. These foods fill the stomach but provide fewer nutrients breast milk.

- Mothers are at greater risks to get pregnant if they breastfeed less frequently.

- Probably increases the risks of topic diseases and type I diabetes mellitus.

Table 2 Risks of giving complementary foods too late

- A child does not get the extra energy and nutrients needed.

- A child stops growing slowly.

- Increase the risks of malnutrition or micronutrient deficiencies.

Source: (PAHO/WHO, 2003) Guiding principles for complementary feeding of the breastfed child.

\section{METHODS AND MATERIALS}

\subsection{Description of the study area}

Jimma Genneti is one of the 10 Districts found in Horo Guduru Wollega Zone and is located to the southern part of the zone, at $27 \mathrm{~km}$ to the south of Shambu town, capital city of the zone and $314 \mathrm{~km}$ from Addis Ababa, capital city of the country. It is sub-divided in to 12 farmer associations and 2 towns for its administrative purpose. The district is bordered by: In the south by East wollega Zone, In south west by East welega Zone, In the West by Horo district, In the North west by Horo and In the east by Guduru district.In the east south by Jimma Rare district. 


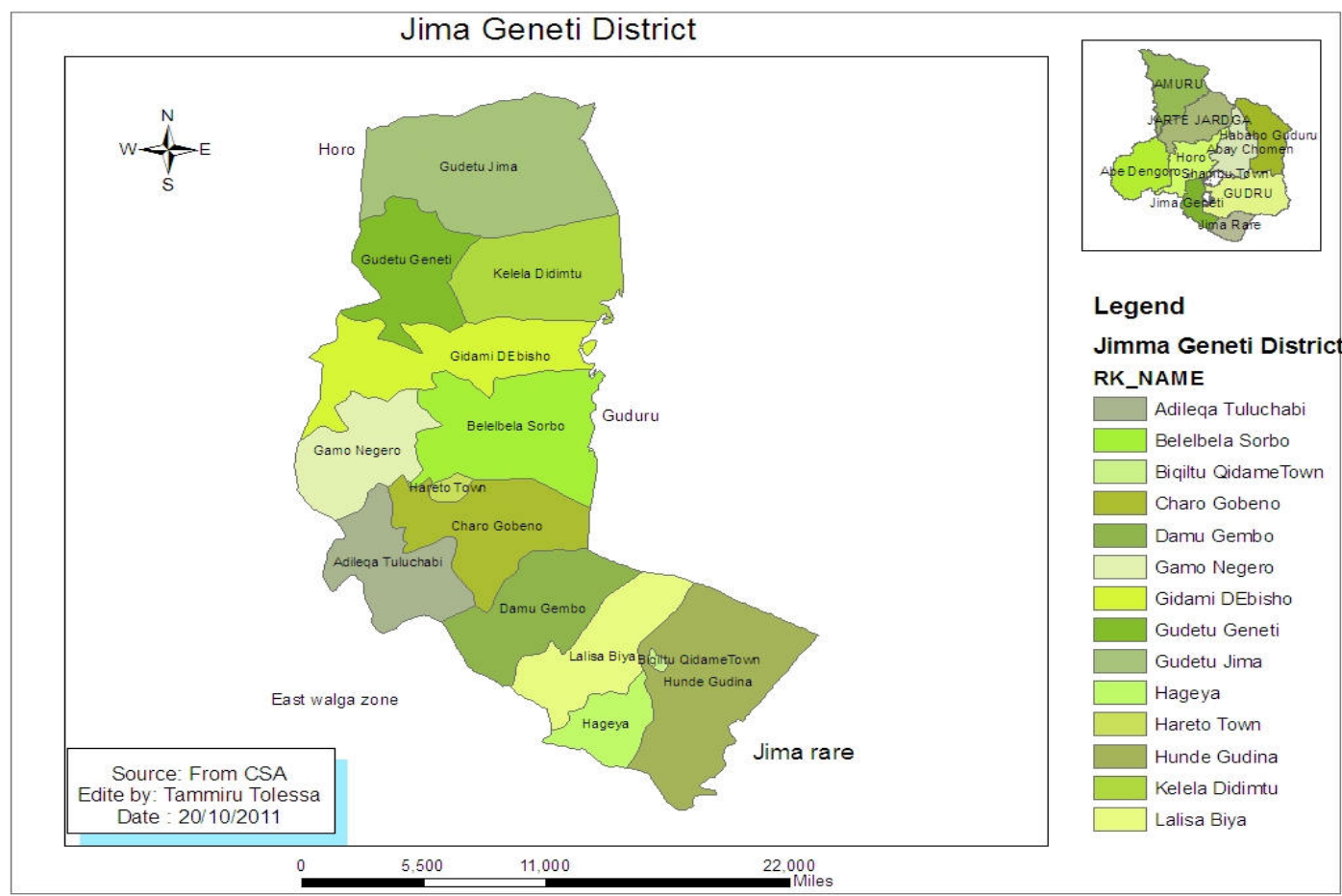

The altitude range of the district is from $1900 \mathrm{~m}$ to $3000 \mathrm{~m}$ above sea level. The District is situated at an altitude $1900 \mathrm{~m}$ above sea level and the dominant climatic condition is sub-tropical climate type. The mean annual rain fall of the District is about $1600 \mathrm{~mm}-2000 \mathrm{~mm}$ and has a mean annual temperature between $15^{\circ} \mathrm{c}$ and $20^{\circ} \mathrm{c}$ (degree Celsius). Estimated total population in 2015 is 91,078 projected based on 2014 census. From this about 80,331 of the district's population are settled in rural and only 10,747 live in urban areas. When this is computed in to percentage, $11.8 \%$ are urban people; whereas $88.2 \%$ are rural with strong indication that most of the people of Jimma Geneti Woreda was living in rural areas (CSA projection, 2015). The crude density of population in the area is 171 people per sq. $\mathrm{km}$.

\subsection{Source of Population}

All mothers living in Jima Ganati who have young children aged 6-23 months were considered as the source of population. The study population was volunteer mothers who have young children whose age 6-23 months in randomly selected kebeles' in Jima Ganati district western Ethiopia.

\subsection{Inclusion criteria and exclusion criteria}

The study participants were mothers who have child in age group from 6-23 months old and who have lived in the study area. The exclusion criteria for the study will mothers/ caregivers who were critically ill and have hearing impairment in study area. People who are not resident, family who are not volunteer and who have no infants were excluded from the data.

\subsection{Sample size Determination}

The sample size of the study was determined by considering the following assumptions the proportion of mothers who inappropriately complementary feed their children to be $31 \%$ with marginal error, $95 \%$ confidence interval, and $10 \%$ is a non response rate. So, the following formula was used to decide the sample size (EDHS, 2011)

Where; $\mathrm{n}=$ sample size

$$
\mathbf{n}=\frac{(\mathbf{Z \alpha / 2})^{2} \cdot \mathbf{p} \cdot \mathbf{q}}{\mathbf{d}^{2}}
$$

$\mathbf{Z \alpha} / \mathbf{2}=$ Value corresponding to a $95 \%$ level of significant $=\mathbf{1 . 9 6} ; \mathbf{d}=$ margin of error $(5 \%=0.05)$

$\mathbf{p}=$ Expected proportion of practices of mothers on, $\mathrm{IYCF}=31 \%=0.31$

$\mathbf{q}=1-\mathrm{p}$ and hence, $\mathrm{q}=0.69$

$\mathbf{n}=\frac{(\mathbf{1 . 9 6})^{2} \times \mathbf{0 . 3 1} \times \mathbf{0 . 6 9}}{(\mathbf{0 . 0 5})^{2}}=\mathbf{3 2 9}+(10 \%$ none response rate $)$, then, $\mathbf{n}=\mathbf{3 2 9}+\mathbf{3 3}=\mathbf{3 6 2}$ 


\section{3 .5. Sampling Techniques}

The Woreda has 12 kebeles and 2 towns and five kebeles were selected purposefully; from each kebele the mothers who have children between age of 6-23 months were selected by lottery method. From five kebeles

\begin{tabular}{|c|c|c|c|c|}
\hline Lalisa Biya & Gidami Dabsho & Gudatu Jima & Kalala Didimtu & Gamo Nagaro \\
\hline $\mathbf{n}_{\mathbf{1}}=189$ & $\mathbf{n}_{2}=300$ & $\mathbf{n}_{3}=295$ & $\mathbf{n}_{4}=283$ & $\mathbf{n}_{5}=200$ \\
\hline 67 & 96 & 72 & 70 & 57 \\
\hline
\end{tabular}

Figure 2: showing the sampling technique of the study population in the study area

\subsection{Method of Data analysis}

Both descriptive statistics and binary logit model were used to investigate the relationship between mothers knowledge of mothers, on complementary feeding and child nutritional status of child's. Measures of height in centimeters (to the nearest $0.1 \mathrm{~cm}$ ) and weight in kilograms to (the nearest $0.1 \mathrm{~kg}$ ) for every child were taken using a weighing scale with an attached height meter (Seca) provided at the Hareto health centers and from selected kebeles'health extension office. The derivation of the logit model begins from the linear probability model of the form:

$$
\begin{aligned}
& P\left(y={ }_{z^{z i}} / x\right)=\mathrm{Zi}=\beta_{0}+\beta_{1} x_{1}+\beta_{2} x_{2}+---+\beta_{k} x_{k}--------(1) \\
& P \boldsymbol{i}=\frac{1+e^{z i}}{\mathbf{r}}
\end{aligned}
$$

Where, $\mathrm{Pi}$ is the probability that the $\mathrm{i}^{\text {th }}$ woman will have complementary feeding knowledge and $\mathrm{z}_{\mathrm{i}}$-is a linear function of $\mathrm{n}$ explanatory variables $(\mathrm{x})$ and will be expressed as:

$$
\mathrm{Zi}=\beta_{0}+\beta_{1} x_{1}+\beta_{2} x_{2}+---+\beta_{k} x_{k}+U i---------------(3)
$$

Where, $\beta$ o - intercept, $\beta i$ - regression coefficients to estimate, $\mathrm{U}_{\mathrm{i}}-$ is an error term.

$$
1-P i=\frac{1}{1+e^{z i}}
$$

Where $1-\mathrm{Pi}$ is the probability that a woman will not have complementary feeding knowledge.

$$
\left(\frac{\mathrm{Pi}}{1-\mathrm{Pi}}\right)=\left(1+\frac{\mathrm{e}^{\mathrm{zi}}}{1+\mathrm{e}^{-\mathrm{zi}}}\right)=\mathrm{e}^{\left(\beta_{0}+\beta_{1} x_{1}+\beta_{2} x_{2}+---+\beta_{k} x_{k}\right)}-----(5)
$$

This is known as Odds ratio. Taking the natural logarithm of the Odds ratio, the logit model is:

$$
\mathrm{Li}=\ln \left[\frac{\mathrm{Pi}}{1-\mathrm{Pi}}\right]=\ln \mathrm{e}^{\left(\beta_{0}+\beta_{1} x_{1}+\beta_{2} x_{2}+---+\beta_{k} x_{k}\right)}=\beta_{0}+\beta_{1} x_{1}+\beta_{2} x_{2}+---+\beta_{k} x_{k}
$$

Where $\mathrm{x}_{1}, \mathrm{x}_{2},-----\mathrm{x}_{\mathrm{k}}$ are demographic, social, knowledge and nutritional status factors which will be included in the above econometric model.

\section{Discussion}

Out of 362 mothers who were eligible for the study 353 mothers were volunteer to participate and $9(2.55 \%)$ refused to participate the nine dropouts due to sick of mothers and infants . The response rate was 97.5\%. As showed in (table 1) the age of mother considered in the study was (15-49) years. This is a child bearing age. Out of 353 children participated in the study $123(34.8 \%)$ were males and $230(65.2 \%)$ were females. When the young children grouped according to their age $173(49 \%), 106(30.1 \%)$ and $74(20.9 \%)$ were $6-12,13-18$ and $19-23$ months respectively. Of total mothers' interviewed most of them; 197 (55.8\%) were aged 21-30 followed by 73 (20.6\%) aged 31-40 years, $68(19.3 \%)$ were $15-20$ aged, the rest $15(4.2 \%)$ more than 41 years old respectively. 
Table 1. Shows the socio-demographic characteristics of the selected kebeles in Jima Ganati district, Oromia Region, Ethiopia from January to June 2018.

\begin{tabular}{|c|c|c|c|}
\hline Variables & category & Frequency & Percents \\
\hline \multirow[t]{4}{*}{ Age of infants } & 6-12 Months & 173 & 49 \\
\hline & 13-18 months & 106 & 30.1 \\
\hline & $19-23$ months & 74 & 20.9 \\
\hline & Total & 353 & 100 \\
\hline \multirow[t]{3}{*}{ Sex of infants } & Male & 123 & 34.8 \\
\hline & Female & 230 & 65.2 \\
\hline & Total & 353 & 100 \\
\hline \multirow[t]{5}{*}{ Age of mothers } & $15-20$ & 68 & 19.3 \\
\hline & $21-30$ & 197 & 55.8 \\
\hline & $31-40$ & 73 & 20.6 \\
\hline & $\geq 41$ & 15 & 4.2 \\
\hline & Total & 353 & 100 \\
\hline \multirow{5}{*}{ Marital status } & Married & 315 & 89.2 \\
\hline & Divorced & 21 & 5.9 \\
\hline & Widowed & 13 & 3.8 \\
\hline & Single & 4 & 1.1 \\
\hline & Total & 353 & 100 \\
\hline \multirow[t]{5}{*}{ Religion } & Orthodox & 116 & 32.7 \\
\hline & Protestant & 211 & 59.8 \\
\hline & Muslim & 17 & 4.8 \\
\hline & Others & 9 & 2.7 \\
\hline & Total & 353 & 100 \\
\hline \multirow[t]{4}{*}{ Ethnicity } & Oromo & 325 & 92.9 \\
\hline & Amhara & 25 & 7.1 \\
\hline & Others & 3 & 0.8 \\
\hline & Total & 353 & 100 \\
\hline \multirow[t]{6}{*}{ Mother's occupation } & Housewife only & 232 & 65.7 \\
\hline & Merchant & 22 & 6.2 \\
\hline & Daily labor & 25 & 7.1 \\
\hline & Government employee & 59 & 16.7 \\
\hline & Other & 15 & 4.2 \\
\hline & Total & 353 & 100 \\
\hline \multirow[t]{5}{*}{ Husband's occupation } & Farmer & 242 & 68.6 \\
\hline & Government employee & 60 & 16.9 \\
\hline & Merchant & 42 & 11.9 \\
\hline & Others & 9 & 2.5 \\
\hline & Total & 353 & 100 \\
\hline \multirow[t]{3}{*}{ Current Residence } & Urban & 118 & 33.4 \\
\hline & Rural & 235 & 66.6 \\
\hline & Total & 353 & 100 \\
\hline \multirow[t]{4}{*}{ Monthly income } & Less than 1000 birr & 91 & 25.8 \\
\hline & 2000 birr & 195 & 55.22 \\
\hline & Greater than 3000 birr & 67 & 18.98 \\
\hline & Total & 353 & 100 \\
\hline \multirow[t]{4}{*}{ Family size } & 3 & 40 & 11.3 \\
\hline & 4 & 83 & 24.1 \\
\hline & 5 and Greater than 5 & 230 & 64.6 \\
\hline & Total & 353 & 100 \\
\hline \multirow[t]{4}{*}{ Relation to child/infant } & Mother & 339 & 96 \\
\hline & Grandmother & 9 & 2.6 \\
\hline & Other & 5 & 1.4 \\
\hline & Total & 353 & 100 \\
\hline
\end{tabular}




\begin{tabular}{|l|c|c|c|}
\hline Variables & category & Frequency & Percents \\
\hline \multirow{4}{*}{ Mothers educational level } & & Frequencies & percent \\
\cline { 2 - 4 } & Categories & 93 & 26.3 \\
\cline { 2 - 4 } & No education & 80 & 22.7 \\
\cline { 2 - 4 } & Read and write & 125 & 35.4 \\
\cline { 2 - 4 } & Primary school & $\mathbf{3 5 3}$ & 15.6 \\
\hline \multirow{3}{*}{ Husband educational level } & Tecondary school \& above & 80 & $\mathbf{1 0 0}$ \\
\cline { 2 - 4 } & No education & 145 & 26.9 \\
\cline { 2 - 4 } & Read and write & 71 & 39.4 \\
\cline { 2 - 4 } & Primary \& secondary school & 57 & 17.6 \\
\cline { 2 - 4 } & 2Secondary school & $\mathbf{3 5 3}$ & 16.1 \\
\cline { 2 - 4 } & Total & $\mathbf{1 0 0}$ \\
\hline
\end{tabular}

The finding of these study identified that 235(66.6\%) of house hold had more than five of family members. Around $118((33.4 \%)$ of house hold contained $<5$ (five) family members. Majority of the respondents $232(65.7 \%)$ were house wife and most residences $235(66.6 \%)$ of the respondents were rural.

Table 2: Assessing of mothers/ caregivers knowledge towards complementary feeding for infants children

\begin{tabular}{|c|c|c|c|c|c|c|}
\hline \multirow{2}{*}{\multicolumn{2}{|c|}{ Variable }} & \multicolumn{2}{|c|}{ Frequency } & \multicolumn{2}{|c|}{ percent } & \multirow[t]{2}{*}{ Total } \\
\hline & & Yes & No & Yes & No & \\
\hline \multicolumn{2}{|l|}{ Know correct definition of Complementary Feeding. } & 238 & 115 & 67.4 & 32.6 & $353(100 \%)$ \\
\hline \multicolumn{2}{|l|}{ Knowledge about food staff/balance diet. } & 184 & 169 & 52.1 & 47.9 & $353(100 \%)$ \\
\hline \multicolumn{2}{|l|}{ Knowledge about source of protein. } & 198 & 155 & 56.1 & 43.9 & $353(100 \%)$ \\
\hline \multicolumn{2}{|l|}{ Knowledge about CF start. } & 211 & 142 & 59.8 & 40.2 & $353(100 \%)$ \\
\hline \multicolumn{2}{|l|}{ Knowledge about carbohydrate } & 197 & 156 & 55.8 & 44.2 & $353(100 \%)$ \\
\hline \multicolumn{2}{|l|}{ Knowledge about inappropriate CF } & 216 & 137 & 61.2 & 38.8 & $353(100 \%)$ \\
\hline \multicolumn{2}{|l|}{ Knowledge about any food rich in vitamin } & 187 & 166 & 53 & 47 & $353(100 \%)$ \\
\hline \multicolumn{2}{|l|}{ Knowledge about starting CF too late risk } & 288 & 65 & 81.6 & 18.4 & $353(100 \%)$ \\
\hline \multicolumn{2}{|c|}{ Knowledge on merits of preparing foods from different crops. } & 228 & 125 & 64.6 & 35.4 & $353(100 \%)$ \\
\hline \multicolumn{2}{|l|}{ Knowledge about the food that contain minerals } & 163 & 190 & 46.2 & 53.8 & $353(100 \%)$ \\
\hline \multicolumn{2}{|l|}{ Overall level of knowledge } & \multicolumn{3}{|c|}{ Frequency } & \multicolumn{2}{|r|}{ Percent } \\
\hline Good & \multicolumn{4}{|c|}{205} & \multicolumn{2}{|r|}{58.1} \\
\hline poor & \multicolumn{4}{|l|}{148} & \multicolumn{2}{|l|}{41.9} \\
\hline Total & \multicolumn{4}{|c|}{353} & \multicolumn{2}{|r|}{100} \\
\hline
\end{tabular}

Inappropriate feeding practices and low quality complementary foods are as significant cause of the higher burden of the child under nutrition worldwide (WHO, 2003). Majority of the respondents 228(64.6\%) had knowledge about advantage of preparing foods from different crops and $125(35.4 \%)$ had no knowledge on Varity/different foods giving for infants/young children. In general, the knowledge assessing this study pointed out $(59.8 \%)$ of the respondents were found to be with good knowledge about complementary feeding for infant/young children.

As in table 3 presented $246(69.7 \%)$ of the respondents agreed about the risks of starting complementary feeding too late on child and 107 (30.3\%) did not agree. It is good to give breast milk up to six month as explained by $195(55.2 \%)$ of the respondents but, $158(44.8 \%)$ of the respondents had negative attitude on it. According to $213(60.3 \%)$ of the respondents inadequate complementary food intake affects health and $140(39.7 \%)$ respondents disagree on it. 
4.2. Results of binary logit model: knowledge of mother on complementary feeding Table 3: Result of Logistic regression and Marginal Effects after Logit.

\begin{tabular}{|l|l|l|l|l|l|l|}
\hline & Logit estimation & \multicolumn{3}{l|}{ Marginal Effects } \\
\hline Knowledge of mother on Compl. feeding & Coef. & Std. Err. & $\mathbf{z}$ & $\mathbf{P}>|\mathbf{z}|$ & Std. Err. & $\mathbf{D y} / \mathbf{d x}$ \\
\hline Age of mother & $2.04068^{* * *}$ & 0.622824 & 2.28 & 0.001 & 0.12192 & 0.47003 \\
\hline Education level of mother & $0.86379^{* * *}$ & 0.767502 & 1.13 & 0.000 & 0.18584 & 0.42603 \\
\hline Educational level of the husband & -1.61646 & 0.778102 & -1.08 & 0.138 & 0.17085 & -0.37858 \\
\hline Monthly income & $2.58652^{* * *}$ & 0.734339 & 3.52 & 0.000 & 0.11366 & 6.56321 \\
\hline Family size & $-0.4919^{* * *}$ & 0.411724 & -3.19 & 0.000 & 0.10013 & 0.115555 \\
\hline Employment status of mother & $-0.02514^{* *}$ & 0.011357 & -2.21 & 0.027 & 0.00255 & -0.3567 \\
\hline Marital status of & -0.09406 & 0.034191 & -2.75 & 0.216 & 0.00772 & 0.1212 \\
\hline Religion & -0.00882 & 0.066262 & -0.13 & 0.894 & 0.01493 & -0.00199 \\
\hline
\end{tabular}

Source: From survey data (2018)

$* * *, * *$ shows significance levels at $1 \%$ and $5 \%$.

Age coefficient is significant at $1 \%$ significance level influencing mothers's complementary feeding knowledge positively. A one year increase in age of a mother has a more probability to get knowledge on complementary feeding. As age of the mother increases by one year, the probability of getting knowledge on complementary feeding increases by $0.47 \%$ marginal effect, holding other variables constant. The coefficient on the family size is significant at $1 \%$ significance level with negative sign. It puts forward that a mother who has more number of families is less likely to have good knowledge on complementary feeding as compared to a mother who has lesser number of families. Its marginal effect shows that one additional family member to a family will reduce the likelihood of a mother's to knoledge by $4.49 \%$ marginal effect, holding other factors constant.

The coefficient on the education level of mother is significant at $1 \%$ level of significance with positive sign. This shows that amother with more years of schooling is more likely to complementary feeding knowledge as compared to those with less years of schooling. Its marginal effect shows that one additional year of schooling of a mother will increase the probability (the likelihood) of the complementary feeding knoledge by $0.426 \%$ marginal effect, holding other factors constant. A complementary feeding knowledge for a mother who has more monthly income increases by $65.60 \%$ marginal effect, holding other factors constant. The coefficient on the employment status of mother is significant at 5\% level of significance with negative sign. It puts forward that an employed mother is busier to give care for her child as compared to unemployed mother. A complementary feeding knowledge for an employed mother decreases by $0.356 \%$ marginal effect, holding other factors constant.

\subsection{Nutritional Status of infant/young children (6-23) months.}

The nutritional status of infants/young children weight for age was measured by kilogram $(\mathrm{kg})$, nearest to $0.1 \mathrm{~kg}$ and height for age measured by centimeter $(\mathrm{cm})$, nearest to $0.1 \mathrm{~cm}$. Anthropometric data weight and height of 6-23 months children was taken and used in the evaluation of the nutritional status of the children. The nutritional status of children was measured by Height for-age to determine how the child was stunted and Weight- for- age, to compares the weight of the child with the weight of a healthy reference child of the same age times hundred based on WHO Growth standards classification to determine overweight and underweight of the child.

Table4: Anthropometric measurement of children 6-23 months in Jima Ganati Woreda 2018

\begin{tabular}{|l|c|c|c|c|}
\hline Variable & Range & Category & Frequency & Percent \\
\hline \multirow{4}{*}{ Height for age } & $>95$ & Normal & 285 & 80.6 \\
\cline { 2 - 5 } & $<95$ & Stunted & 68 & 19.4 \\
\cline { 2 - 5 } & & Total & $\mathbf{3 5 3}$ & $\mathbf{1 0 0}$ \\
\hline \multirow{4}{*}{ Weight for age } & $>110$ & Overweight & 10 & 2.9 \\
\cline { 2 - 5 } & $90-110$ & Normal & 265 & 75 \\
\cline { 2 - 5 } & $<90$ & Underweight & 78 & 22.1 \\
\cline { 2 - 5 } & & Total & $\mathbf{3 5 3}$ & $\mathbf{1 0 0}$ \\
\hline Weight for height & $>90$ & Normal height & 323 & 8.5 \\
\cline { 2 - 5 } & $<90$ & Wasted & 30 & $\mathbf{1 0 0}$ \\
\cline { 2 - 5 } & & Total & $\mathbf{3 5 3}$ & \\
\hline
\end{tabular}

\section{Conclusion}

The study was conducted on complementary feeding knowledge, of mothers/ caregivers and nutritional status of infants in Jima Ganati woreda, Horo Guduru Wollega zone, Ethiopia. Based on the present study, it can be conclude that the highest respondents $(39.4 \%)$ were without formal education where as the lowest respondents (16.1\%) have completed secondary school and above level of education. This finding showed that (69.4\%) of the respondents started complementary food at 6-8 months age of their child. In binary logit output age, educational 
level of mothers, family size and mother's monthly income are all affecting complementary feeding knowledge of mothers significantly and positively. This study revealed that low income families have the highest rates of wasting and stunting.

Based on the findings of the study, the following recommendations are made:

* Need to expand a programmer which links nutrition interventions and social protection in low income urban communities in order to reach young children.

* Strengthen and integrate counseling of mothers on appropriate child feeding knowledge by providing training on infant feeding and feeding options recommended to the children.

* Need to increase awareness about family planning especially its importance for optimal growth of children in the community.

* Need to give nutrition education for the community about maternal and child nutrition to accelerate prevention of stunting by focusing the most critical periods of child development.

\section{ACKNOWLEDGEMENTS}

First and foremost my sincere gratitude and thanks to the Almighty God, who supplied the strength and capability to accomplish this work. I highly appreciate the staff members of Jima Ganati health Buruae for their hospitality and patience to necessary information during the data collection. I forward my special thanks to my wife Kiya Emiru Galata for her continuous moral support during the study. Last but not least, many thanks to my extremely supportive brothers Dachasa Emiru, Taressa Birru and Geremew Birru who have a great contribution in data collection and moral support during my entire work.

\section{References}

Agumasie Semahegn, Alemayehu and Bogale (2014) complementary feeding Practice of mothers and associated factors in Hiwot Fauna Specialized Hospital, Eastern Ethiopia. The pan African Medical Journal.2014; 18: 143

Cristina M.G.Monte,Elsa R.J.Giugliani ,(2004) Recommendations for the complementary Feeding of the breastfed child, Journal de Pediatric; 80(5 Supple): S 131-S141.

Desslegn Tamiru,Dayan Aragu,Tefera Belachew,2013.Survey on the Introduction of Complementary foods to infants with in the first six months and associated factors in Rural communities of Jima Arjo;2(23):77-84

Egata.G.Y. Berhane, A.Worku.2013."Predictors of non-exclusive breastfeeding at six months Among rural mothers in east Ethiopia: community based analytical cross sectional Study "International breast feeding Journal 8(1):8

Jacob Kipruto Korir, Determinants of complementary feeding feeding practices and nutritional Status of children (6-23months) old in Nairobi, Kenya 2013.

Knoweldge and practices of Mothers of infants and young children of complementary feeding (2012),in paediatrics of National Academy Medical Science Mahabaudha Kathmandu, Nepal, MD thesis National Academy Medical Science,Mahabaudha.

Pandey S, Tiwari K, Senarath U, Agho KE and Bibley MJ. Determinants of infant and young Child feeding practices of Nepal: Secondary data analysis of 2006 EDS.Food and Nutrition bulletin 2010;31(2):334-51.

Samson Yemane, Tadesse, Awoke, Measho initiation of complementary feeding practice and Associated factor among mothers of children aged from 6 to24 months in Axum town, North EthiopiaInternationalJournal of Nutrition and food sciences. Vol.3,No5, 2014.

Tamariu D and S.Mohammed.2013“.Matternal knowledge of optimal breastfeedig practices and Associated factors in rural communities of Arbaminch zuria " international journal of Nutrition and food sciences 2(3):122-129.

World Health Organization. Infant and young children feeding model chapter for medical Professional and allied health professional. Geneva: World Health Organization; 2010. 